\title{
Ethology, Sociobiology, and Evolutionary Psychology
}

\author{
Paul E. Griffiths \\ Biohumanities Project \\ University of Queensland \\ Brisbane, QLD 4072 \\ Australia \\ paul.griffiths@uq.edu.au
}

\begin{abstract}
"It is only a comparative and evolutionary psychology that can provide the needed basis; and this could not be created before the work of Darwin" William McDougall, Introduction to Social Psychology, 1908.
\end{abstract}

\section{A century of evolutionary psychology}

The evolution of mind and behavior was of intense interest to Charles Darwin throughout his life. His views were made public a decade before his death in The Descent of Man (e.g. 1981 [1871]) and The Expression of the Emotions in Man and Animals (1965 [1872]). Evolutionary psychology has been an active field of research and a topic of public controversy from that time to the present. At least four distinct phases can be distinguished in the development of evolutionary psychology since Darwin and his immediate successor George Romanes. These are: instinct theory, classical ethology, sociobiology and Evolutionary Psychology, the last of which I capitalize to distinguish it from evolutionary psychology in general.

The instinct theories of Conwy Lloyd Morgan, James Mark Baldwin, William James, William McDougall and others were an important part of early $20^{\text {th }}$ century psychology (Richards 1987) but will not be discussed here, because no trace of these theories can be discerned in evolutionary psychology today. It was not until the years leading up to the Second World War that the ethologists Konrad Lorenz and Nikolaas Tinbergen, created the tradition of rigorous, Darwinian research on animal behavior that developed into modern behavioral ecology (Burkhardt 2005). At first glance, research on specifically human behavior seems to exhibit greater discontinuity that research on animal behavior in general. The 'human ethology' of the 1960s appears to have been replaced in the early 1970 s by a new approach called 'sociobiology'. Sociobiology in its turn appears to have been replaced by an approach calling itself Evolutionary Psychology. Closer examination, however, reveals a great deal of continuity between these schools. Whilst there have been genuine changes, many of the people, research practices and ideas of each school were carried over into its successors. At present, whilst Evolutionary Psychology is the most visible form of evolutionary psychology, empirical and theoretical research on the evolution of mind and behavior is marked by a diversity of ideas and approaches and it is far from clear which direction(s) the field will take in future. 


\section{The study of instinct}

In the period immediately following the First World War many psychologists rejected the previously uncontroversial idea of human instinct. This rejection reflected a number of concerns, including the fear that classifying behaviors by their biological function would not create natural psychological or neurological groupings, and the view that 'instinct' was a pseudo-scientific substitute for causal explanation (Dunlap 1919; Kuo 1921). The concept of instinct was reconstructed in a fresh and more viable form in the mid-1930s, primarily in the work of Konrad Lorenz. In his view, "the large and immeasurably fertile field which innate behaviour offers to analytic research was left unploughed because it lay, as no man's land, between the two fronts of the antagonistic opinions of vitalists and mechanists" (Lorenz 1950, 232). Lorenz criticized the behaviorists for reducing the biological endowment of animals to a small number of reflex reactions destined to be assembled into complex adult behaviors by associative learning. But he was also a stern critic of the vitalistic theories of instinct propounded by McDougall and by the leading Dutch comparative psychologist Abraham Bierens de Haan. In his criticism of these authors Lorenz rejected the traditional picture of instincts such as 'parenting', which influence the production of many specific behaviors. Instead, Lorenz argued that when a bird 'instinctively' feeds its offspring it has no motivation beyond an immediate drive to perform the act of regurgitation in the presence of the stimulus presented by the begging chick. The appearance of an overarching 'parenting instinct' is produced by the interaction of a large number of these highly specific instincts and the stimuli (and self-stimuli) which impact the bird in its natural environmental setting. But whilst traditional instincts were too nebulous for Lorenz, he was convinced that the mechanistic substitutes envisaged by behaviorism - reflexes and tropisms - were inadequate to explain the rich repertoire of instinctive behaviors. Lorenz was committed to the ultimate reduction of instincts to neural mechanism, but such neural mechanisms, he believed, would be far more sophisticated than mere chain reflexes, or tropisms. It is here that we find the significance of Lorenz's famous drive-discharge or 'hydraulic' model of instinctual motivation (Figure 1). The hydraulic model was complex enough to account for the observed behavior, but simple enough that it might in future be directly mapped onto neural pathways and humoural influences on those pathways. 


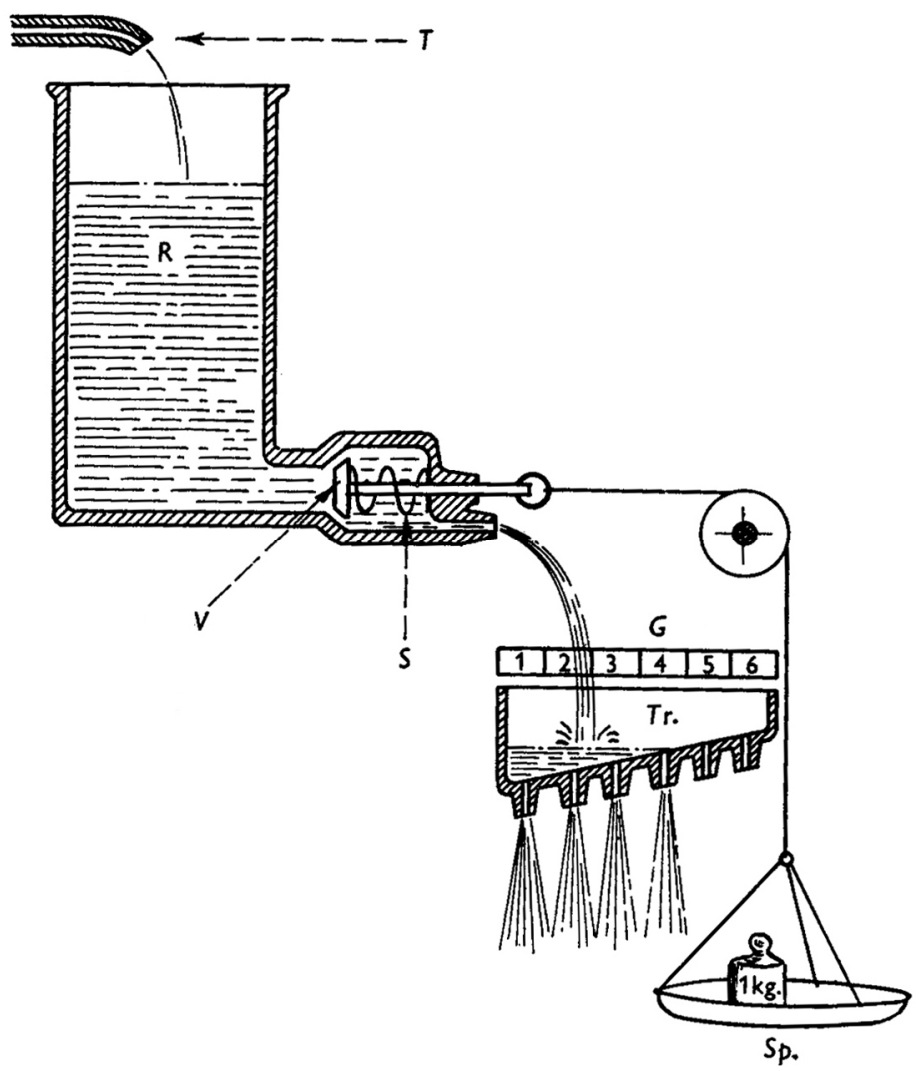

Figure 1. The 'hydraulic model' of instinctual motivation (Lorenz 1950, 256)

Drawing on ideas from contemporary neuroscience, Lorenz suggested that the nervous system continuously generates impulses to perform instinctive behaviors, but that the behaviors manifest themselves only when special inhibitory mechanisms are 'released' by an external stimulus. Using a mechanical analogy, Lorenz pictured each instinct as a reservoir in which a liquid ( $\mathrm{R})$ continually accumulates. The outlet of the reservoir is blocked by a spring-loaded valve (V) which can be opened by presentation of a highly specific sensory 'releaser' (Sp). When the valve is opened, the contents of the reservoir ('action specific energy') flow to motor systems and produce the instinctual behavior pattern. A signal virtue of the hydraulic model, according to Lorenz, is that it captures the apparent spontaneity of some animal behavior: if no releasing stimulus is available, then pressure can accumulate to the point where the valve is forced open and the animal performs instinctive behaviors 'in a vacuum'. Lorenz regarded the observed phenomenon of 'vacuum activities' as one off the most critical clues to the nature of instinctual motivation. Another form of spontaneous behavior to which Lorenz drew attention was 'appetitive behavior' - behavior which increases the probability of finding a releasing stimulus for the instinct. He postulated that the accumulation of action specific energy in the reservoir directly causes appetitive behavior. Thus, when external factors such a daylength put it in a suitable hormonal state, a bird will initiate appetitive behaviors that result in it coming into contact with nesting materials which act to release instinctive nest-building behaviors. 
A striking feature of Lorenz's instinct theory is that the coordination of instinctive behavior into effective sequences is dependent on the distribution of releasing stimuli in the organism's natural environment. Although each specific instinct - collecting twigs at nesting time, inserting twigs into the nest and so forth - corresponds to a neural mechanism, the larger structure of instinctual behavior only emerges in the interaction between those mechanisms and the organism's natural environment. The environment has thus taken over the role of nebulous coordinating forces like the 'nesting instinct' postulated by earlier instinct theories. It follows that the study of instinctive behavior requires the observation of the organism in its natural environment.

The program of classical ethology was laid out in Tinbergen's The Study of Instinct (1951). The book brought together an impressive body of data and theory concerning animal behavior and showed how far the field had come in recent years, just as Edward O. Wilson's Sociobiology: The new synthesis was to do quarter of a century later (Wilson 1975). In a striking parallel between the two books, Tinbergen concluded with a more speculative chapter in which the spotlight of the new science was turned on the human mind. But in contrast to the storm that broke over Wilson's head as a result of his chapter on humans, Tinbergen's work was received with general enthusiasm. It played a significant role in the rise of natural history as an entertainment genre in the new medium of television.

The theoretical framework of ethology evolved rapidly in the 1950s and 60s. Three important developments were: 1) The abandonment of Lorenz's identification of instinctive behavior with behavior which is innate as opposed to acquired;2) The abandonment of the hydraulic model; 3) The integration of ethology with evolutionary ecology, resulting in an increased focus on documenting the adaptive value of behavior.

The eclipse of the Lorenzian concept of innateness in Britain is normally attributed to the influence of the American developmental psychobiology in general and Daniel S. Lehrman in particular. Lorenz had denied that the instinctive behavior can be 'fine-tuned' by experience, as earlier instinct theorists had apparently described in cases such as pecking for grain in chickens. Instead, Lorenz insisted that behavior sequences can always be analyzed to reveal specific components that are innate and other components that are acquired. The innate elements, he thought, were to be explained in terms of the endogenous development of underlying nervous tissue - instincts grow in much the same way as limbs. Lehrman's famous critique documented the fact that endogenous and exogenous influences on behavioral development interact in numerous ways, and that no one pattern of interaction is distinctive of the evolved elements of the behavioral phenotype (Lehrman 1953). The development of behavior which is instinctive in the sense that it has been designed by natural selection often depends on highly specific environmental influences. Lehrman was also critical of Lorenz's use of the deprivation experiment (raising animals in social isolation and without the ability to practice a behavior) to infer that a behavior is innate simpliciter, rather than merely that the factors controlled for in the experiment are not needed for the development of that behavior. Lehrman had been personally acquainted with Tinbergen since before WWII and many of 
his ideas were incorporated into mainstream ethological theory in Britain (see Tinbergen 1963 423-427). Ethological work in the 1960s displayed a sophisticated understanding of the relationship between developmental and evolutionary explanations.

The Cambridge ethologist Robert A. Hinde was probably the first to argue explicitly that the hydraulic model had outlived its usefulness (Hinde 1956; and see Burkhardt 2005). Lorenz had created a physical analogy which captured certain observations about instinctive behavior. Tinbergen had already recognized the inadequacy of the original model and had suggested a more complex model along the same lines, with a series of hierarchically organized centers of instinctual motivation influencing one another and, eventually, behavior (Tinbergen 1951). But Hinde argued that the implications of the fundamental hydraulic analogy had not been borne out by subsequent research. In particular, any empirically adequate model would have to allow 'energy' to flow back 'uphill' or against the pressure-gradient, thus contradicting the central feature of the analogy. Reliance on the hydraulic model in ethological research was replaced by empirical research on the neurological factors affecting instinctual behavior. Research on the endocrine system was particularly prominent, because this was experimentally tractable at the time.

The third major theoretical development in animal behavior research in the 1950s and 1960s resulted not from external or internal critique, but from the fusion of ethology with a powerful existing British research tradition. Lorenz thought of ethology as the application to behavior of the principles of comparative morphology, the science in which he had been trained as in Vienna as a young man. This led him to reject the orthodox view that behavior is more evolutionarily labile than anatomy: "Such innate, species-specific motor patterns represent characters that must have behaved like morphological characters in the course of evolution. Indeed, they must have behaved like particularly conservative characters." (Lorenz 1996 [1948], 237, his emphases). In British ethology, this emphasis on behaviors as taxonomic characters was replaced by an emphasis on behaviors as adaptations, a change which reflected the greater role of evolutionary ecology in post-synthesis evolutionary biology in Britain, and particularly in Oxford (Burkhardt 2005). As Tinbergen noted:

"Being a member of the Oxford setup gave me the unique chance to absorb through daily personal contacts, the typical ecology and evolution study-oriented atmosphere of Oxford zoology. Life in this academic community...influenced my entire outlook, and the group I now began to build up, from very modest beginnings indeed, began to produce work with a distinctly Oxonian flavour' (Tinbergen 1985: 450-451; see also Tinbergen 1963).

David Lack, the dominant figure in Oxford ornithology at this time, focused on the ecological functions of bird behavior. A similar emphasis was soon apparent in the work of Tinbergen and his students on the comparative behavior of seabirds, most famously in Esther Cullen's ground-breaking studies of the cliff-nesting adaptations of the Kittiwake. Similarities and dissimilarities between species were interpreted in terms of differing selection regimes as well as, and increasingly instead of, taxonomic relationships. 
The mature ideas of the 'Tinbergen school' were embodied in the influential programmatic paper 'On the aims and methods of ethology' (1963). Tinbergen began with his favoured definition of ethology: 'the biology of behavior'. Building on previous analyses by Julian Huxley and Ernst Mayr, he argued that the biological study of an organism asks four questions:

1. Causation

2. Survival value

3. Ontogeny

4. Evolution

Questions of causation ask what mechanism underlies an observed behavior, such as the collection of nesting materials. The hydraulic model was a hypothesis about causation, albeit an inadequate one.

Questions of survival value ask: "whether any effect of the observed process contributes to survival if so how survival is promoted and whether it is promoted better by the observed process than by slightly different processes." This question was the focus of a rich experimental tradition at Oxford, of which H.B.D Kettlewell's studies of industrial melanism in the peppered moth are the most famous example. The mistaken view that survival value cannot be studied by "exact experimentation" Tinbergen argued, reflects "a confusion of the study of natural selection with that of survival value" $(1963,418)$. Even creationists would need to answer questions of survival value: "To those who argue that the only function of studies of survival value is to strengthen the theory of natural selection I should like to say: even if the present-day animals were created the way they are now, the fact that they manage to survive would pose the problem of how they do this." (423, my emphasis)

Questions of ontogeny ask how the mechanisms revealed by the study of causation are built. After Lehrman's intervention work on this question by British ethologists resembled the existing, primarily American, tradition of developmental psychobiology.

Questions of evolution have "two major aims: the elucidation of the course evolution must be assumed to have taken, and the unraveling of its dynamics." $(1963,428)$ The course of evolution is revealed by inferring phylogenies and homologies, as Lorenz had stressed. The dynamics of evolution are revealed by the study of 1) population genetics and 2) survival value (428), studies which correspond to Elliot Sober's (1984) 'consequence laws' and 'source laws' in evolutionary theory. Source laws explain why one type of organism is fitter than another, whilst consequence laws tell us what will happen at the population level in virtue of those differences. The study of survival value, Tinbergen notes, can more or less directly demonstrate the 'stabilising' role of particular selection pressures in the evolutionary present, but to infer a larger, 'moulding' role for those selection pressures in the evolutionary origin of traits we need additional, historical evidence. 
To appear in Blackwell's Companion to Philosophy of Biology, Sarkar, Sarkar and Plutynski, Anya (eds)

Tinbergen's four questions are still used as a framework for research in behavioral biology today (e.g. Manning and Dawkins 1998).

\section{The triumph of adaptationism}

Lorenz, Tinbergen and the discoverer of bee language Karl von Frisch were awarded a joint Nobel Prize in 1973 for their roles in creating a new science of animal behavior. Ironically, the discipline with which they were so strongly identified - ethology - was on the brink of being eclipsed by a new approach to animal behavior - sociobiology. By the mid 1980s one would have been hard pressed to find a young student of animal behavior who regarded their work as a contribution to ethology, as opposed to behavioral ecology or sociobiology. In their books and journals older ethologists were telling the story of the disappearance of their discipline (e.g. Bateson and Klopfer 1989). If some of the more polemical writings of early sociobiologists are to be believed, ethology had never risen above the level of descriptive natural history, and had never assimilated the evolutionary biology of the modern synthesis (Barkow 1979; Barash 1979). But in reality, the 1970s saw, not the triumph of 'sociobiology' over 'ethology', but the triumph of adaptationism within English speaking ethology, so that what can perhaps be most neutrally described as 'behavioral ecology' came to dominate animal behavior studies. By the early 1970s the population genetic models of William D. Hamilton (1964) had created a theoretical tradition that was readily combined with the experimental tradition created by Tinbergen. Behavioral ecologists set out to test the predictions of the new population genetic models through the study of the survival value of different phenotypes in the laboratory and the field. Tinbergen's 'survival value' and 'evolution' questions came to be seen as the primary questions in animal behavior research. Hence, while the term 'sociobiology' was introduced in a revolutionary manner, the research it denoted had come into existence by a far more gradual path. The idea that sociobiology was a break with the past must be primarily credited to Edward O. Wilson, the Harvard biologist who used it as the title of his 1975 book announcing a 'new synthesis' in behavioral biology (Wilson 1975). The term 'sociobiology' had been used in various senses since the 1940s (as in the name of the Ecological Society of America's 'Section of Animal Behavior and Sociobiology'). Wilson recruited it as a label with which to draw attention to the changes that had occurred in animal behaviour research over the previous decade. His book was the subject of public controversy of quite extraordinary intensity, for complex reasons which historians and sociologists of science are only now starting to comprehend (Segerstråle 2000), and 'sociobiology' passed into popular usage as a general term for evolutionary approaches to mind and behavior.

Wilson's book was also the subject of controversy within animal behavior studies, for reasons which are easier to comprehend. In a famous diagram, Wilson predicted that sociobiology would ingest and absorb all those parts of behavioral biology that were not ingested and absorbed by an equally voracious cellular neurobiology (Figure 2). 

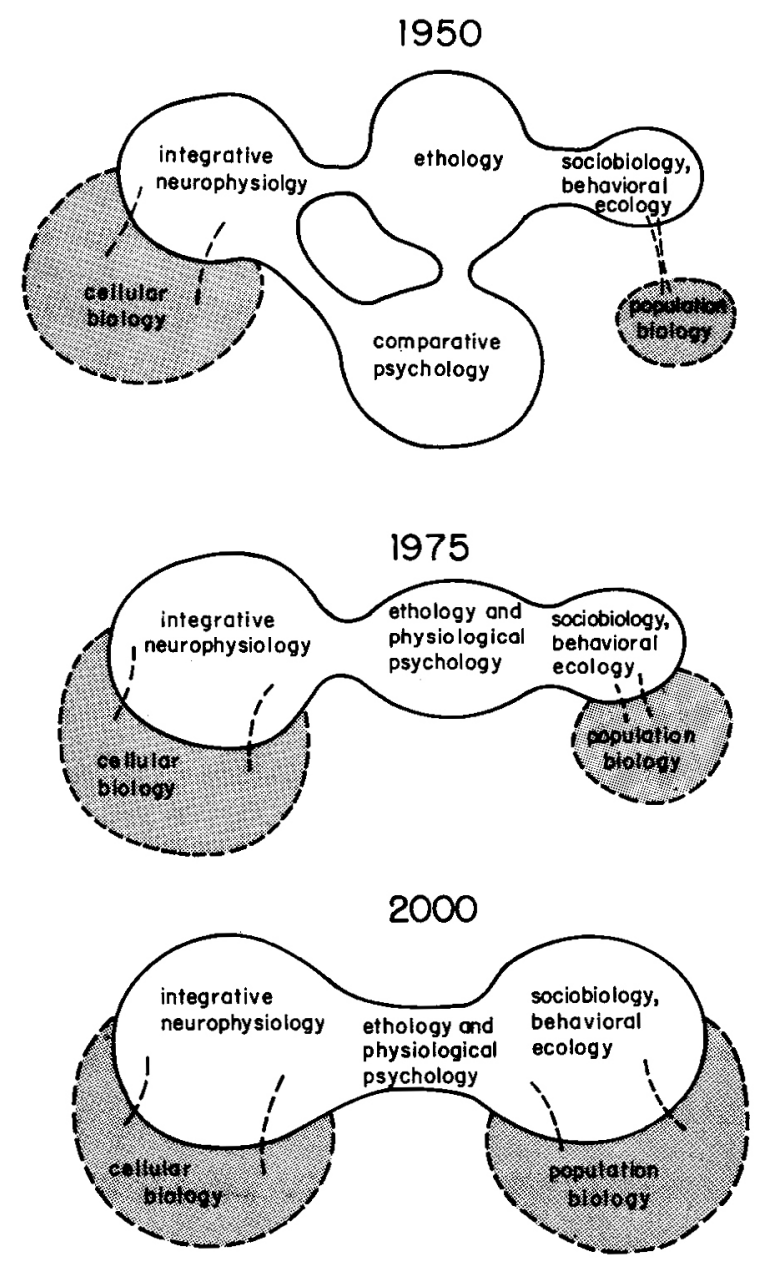

Figure 2. Edward O. Wilson's 1975 depiction of the history and future of animal behavior research.

This vision was not welcomed by the existing community of animal behavior researchers, as is evident from the multi-authored review symposium in Animal Behaviour (Baerends 1976) At the simplest level, ethologists were reacting in a predictable way to being told that their discipline was outmoded, but that was not all that lay behind their response. Wilson's diagram and the accompanying discussion leave no room for major elements of the research agenda laid out in Tinbergen's 'four questions'. In effect, Wilson was trying to reduce Tinbergen's quadripartite distinction to Ernst Mayr's equally well-known bipartite distinction between 'proximate' and 'ultimate' questions in biology. In the process he left out important topics that figured in animal behavior research in the 1960s. Students of behavioral development, for example, did not see themselves fitting into either 'cell biology' or 'population biology'. While their work had a clear role in Tinbergen's ethology it was not part of Wilson's 'new synthesis'. As the leading birdsong researcher Peter Slater has written: "E. O. Wilson (1975), in his 'dumb-bell model', predicted that animal behaviour would be swallowed up by neurobiology at one end and 
sociobiology at the other. As far as song is concerned he has been largely right but only if, as sociobiologists are prone to do, one ignores development." (Slater 2003)

A distinctive feature of the new behavioral ecology/sociobiology was the conviction that Tinbergen's four questions are not, as he himself had thought, closely interlinked. During the 1960s different ethological research groups had come to focus on different parts of the Tinbergian research program (Durant 1986: 1612; see also Burkhardt 2005). Ethology as a discipline ceased to exist when these groups ceased to see themselves as tackling different aspects of the same problem - the biology of behaviour. Researchers like Richard Dawkins, whose favored part of the Tinbergen program was included in the new behavioral ecology, felt no sense of rupture with their earlier work: "My own dominant recollection of [Tinbergen's] undergraduate lectures on animal behaviour was of his ruthlessly mechanistic attitude to animal behaviour and the machinery that underlay it. I was particularly taken with two phrases of his - 'behaviour machinery' and 'equipment for survival'. When I came to write my own first book I combined them into the brief phrase 'survival machine'." (Dawkins, Halliday, and Dawkins 1991: xii). From this perspective The Selfish Gene (Dawkins 1976) differs from The Study of Instinct only because of the smooth progress of scientific knowledge. But researchers whose favored Tinbergian questions were 'causation' and 'ontogeny' found themselves excluded from a new, and highly successful, phase in the study of animal behavior.

It is clear that behavioral ecology/sociobiology and the study of adaptive value and evolutionary origins had a 'comparative advantage' over the study of causation and ontongeny during the 1970s. No new discipline comparable to behavioral ecology arose from the other parts of Tinbergen's program, and the rising generation of animal behavior researchers was predominantly attracted to behavioral ecology. Two possible reasons can be advanced for this. First, behavioral ecology made it possible to see particular studies as tests of general hypotheses about the evolutionary process. Behavioral ecology possessed game theoretic and population genetic models of a very high degree of generality, and a single, practicable study in the field or the laboratory could constitute a test of the predictions of an entire class of models, such as optimal foraging theory or parental investment theory. With the possible exception of the template theory of song acquisition in passerine birds, the study of causation and behavioral development did not offer general theories of a kind whose adequacy could be meaningfully tested in a single series of experiments. It is not difficult to see why a field in which a practicable series of experiments could test an important theory would be more appealing to young researchers than a field in which in which this appeared impossible. Second, the study of behavioral causation and ontogeny was simply not able to keep up with the study of adaptive value, forcing pragmatic researchers to look for ways to make their research independent of answers to such apparently intractable questions. Studies of causation and ontogeny could, in principle, have contributed to behavioral ecology in a very direct way, by determining a realistic 'phenotype set' available for selection to act upon, but in almost all cases those studies were not advanced enough to provide this information. In practice, the phenotype sets of evolutionary models were based on what actually occurs in nature, or on what seemed biologically plausible to the researchers. Hence, instead of developmental biology making a positive contribution to behavioral ecology, it appeared 
only in the negative role of 'developmental constraints' - sets of phenotypes that were inferred on indirect evidence to be in some way unattainable (Maynard Smith et al. 1985). Some researchers argued that the most practicable way to determine the phenotype set was to build models of optimal adaptation and see when they failed to predict the phenotype observed in nature (Maynard Smith 1987). One explanation of an organism's failure to manifest the optimal phenotype is that it is not part of the available phenotype set.

\section{From sociobiology to Evolutionary Psychology}

Human sociobiology straightforwardly applied the methods of behavioral ecology to the human species. Human behaviors were treated as optimal solutions to adaptive problems, or, more usually, as 'evolutionarily stable strategies' in game-theoretic models of competition between organisms (Maynard Smith 1982). An evolutionarily stable strategy, or ESS, is a phenotype such that, if all members of a population have that phenotype, no mutant phenotype can increase in frequency in the population. The ESS concept is the appropriate conception of an evolutionary equilibrium when selection is 'frequency dependent', meaning that the adaptive value of a strategy depends on which strategies are used by the rest of the population. Much human behavioral evolution seems likely to have involved frequency dependent selection. One of the most prominent topics of research in human sociobiology was the evolution of altruistic behavior, which was seen as the key to the evolution of social behavior more generally. The evolutionary problem posed by the existence of altruistic behavior can be made clear using the game matrix known as 'prisoner's dilemma' from the story about two accomplices who are each offered a reduced sentence for betraying the other (Figure 3 ).

\begin{tabular}{l|l|l|l}
\multicolumn{2}{c|}{} & \multicolumn{2}{c}{ Organism 2 } \\
\hline \multirow{3}{*}{ Organism 1 } & Cooperate C & Defect D \\
\cline { 2 - 4 } & Cooperate C & a & b \\
\cline { 2 - 4 } & Defect D & c & d
\end{tabular}

Figure 3. The prisoner's dilemma. The values $c>a>d>b$ are the payoff to organism 1 for each possible pair of phenotypes of organisms 1 and 2.

The important feature of the prisoner's dilemma is that no matter whether organism 2 has the cooperative phenotype $\mathrm{C}$ or the defecting phenotype $\mathrm{D}$, organism 1 will receive a higher payoff if they have the defecting phenotype $D$, since $c>a$ and $d>b$. For example, whether or not organism 2 is willing to share food, organism 1 will do better if they are not willing to share food. Hence D is an evolutionary stable strategy: if everyone in an evolving population has phenotype $\mathrm{D}$ then any mutant with phenotype $\mathrm{C}$ will be selected against. But if both organisms have the defecting phenotype $\mathrm{D}$, they will each only receive payoff $d$. They would be better off if they could both evolve the cooperative phenotype $\mathrm{C}$, since they would then each receive payoff $\mathrm{a}>\mathrm{d}$. But $\mathrm{C}$ is not an evolutionarily stable strategy, because in a population of Cs, a mutant with the D phenotype will do better than the Cs and Ds will eventually come to predominate. One 
well-known solution to this problem proposes that altruistic behaviors can evolve if the competing organisms interact repeatedly during their lifetimes (the 'iterated prisoners dilemma') and if they can make their behavior towards other organisms depend on what happened in previous interactions (reciprocation/retaliation). One way to link past interactions to future ones is by recognizing individuals and remembering their behavior, but simpler mechanisms can produce the same outcome. Organisms with the phenotype TFT (tit-for tat) behave cooperatively in their first encounter with each organism, but in subsequent encounters only cooperate with organisms who cooperated with them in their last encounter. Organisms with the TFT phenotype are 'reciprocal altruists' (Trivers 1971). If the phenotype set contains only the three possibilities C, D and TFT, then TFT is an evolutionarily stable strategy because a population of TFTs cannot be taken over by D mutants. Moreover, under some circumstances TFT mutants can take over in a population composed of Ds. Another solution to the problem of altruism, not necessarily incompatible with the first, draws more directly on Hamilton's work to suggest that altruistic behavior can evolve if the degree of genetic relatedness between the interacting organisms is high enough ('kin selection').

In the late 1980s sociobiology itself came under attack from a new movement calling itself 'Evolutionary Psychology' (Crawford, Smith, and Krebs 1987; Barkow, Cosmides, and Tooby 1992). Evolutionary Psychologists argued that the whole project of explaining contemporary human behaviors as a direct result of adaptive evolution was misguided (Symons, 1992). The contemporary environment is so different from that in which human beings evolved that their behavior probably bears no resemblance to the behavior which played a role in human evolution. This problem had been identified by earlier critics of sociobiology (e.g. Kitcher 1985), but evolutionary psychology followed it up with a positive proposal. Evolutionary theory should be used to predict which behaviors would have been selected in postulated ancestral environments. Human behavior today can be explained as the output of mechanisms that evolved to produce those ancestral behaviors when these mechanisms operate in the very different modern environment. Furthermore, the diverse behaviors seen in different cultures may all be manifestations of a single, evolved psychological mechanism operating under a range of local conditions, an idea that originated in an offshoot of sociobiology known as Darwinian anthropology (Alexander 1979, 1987). Refocusing research on the 'Darwinian algorithms' that underlie observed behavior, rather than the behavior itself, lets the evolutionary psychologist 'see through' the interfering effects of environmental change and cultural difference to an underlying human nature.

Evolutionary Psychology uses the same population genetic and evolutionary game theory models as sociobiology, and there is often little difference in the actual explanations which the two schools offer for human behavior. For example, the classic behavioral ecological explanations of altruistic behavior just discussed are entirely acceptable to Evolutionary Psychologists. Perhaps the best-known experiment in Evolutionary Psychology research was designed to test the hypothesis that humans are reciprocal altruists (Cosmides and Tooby 1992). In this experiment, Linda Cosmides and John Tooby modified an existing psychological task in which subjects are asked if a conditional rule of the form 'If $\mathrm{P}$, then $\mathrm{Q}$ ' holds in a set of cards one side of indicates 
whether the antecedent $(\mathrm{P})$ of the conditional is true and the other side of which indicates whether the consequent $(\mathrm{Q})$ is true (Figure 4). Previous research had shown that many subjects turn over cards whose visible side is marked $\mathrm{Q}$ or $\sim \mathrm{P}$, despite the fact that these cards are irrelevant to the task, and fail to turn over the card marked $\sim \mathrm{Q}$, despite its relevance. When subjects were given a version of the task in which $\mathrm{P}$ and $\mathrm{Q}$ were replaced by statements of the general form 'If you take the benefit, then you pay the cost' and preceded by descriptions which emphasized what Cosmides and Tooby describe as 'social exchange', their performance improved markedly. This result has been used to argue that human psychology has been specifically designed for solving problems to do with 'cheating' and 'free-riding' in social interactions. This in turn has been taken to confirm the importance of reciprocal altruism in human evolution. 


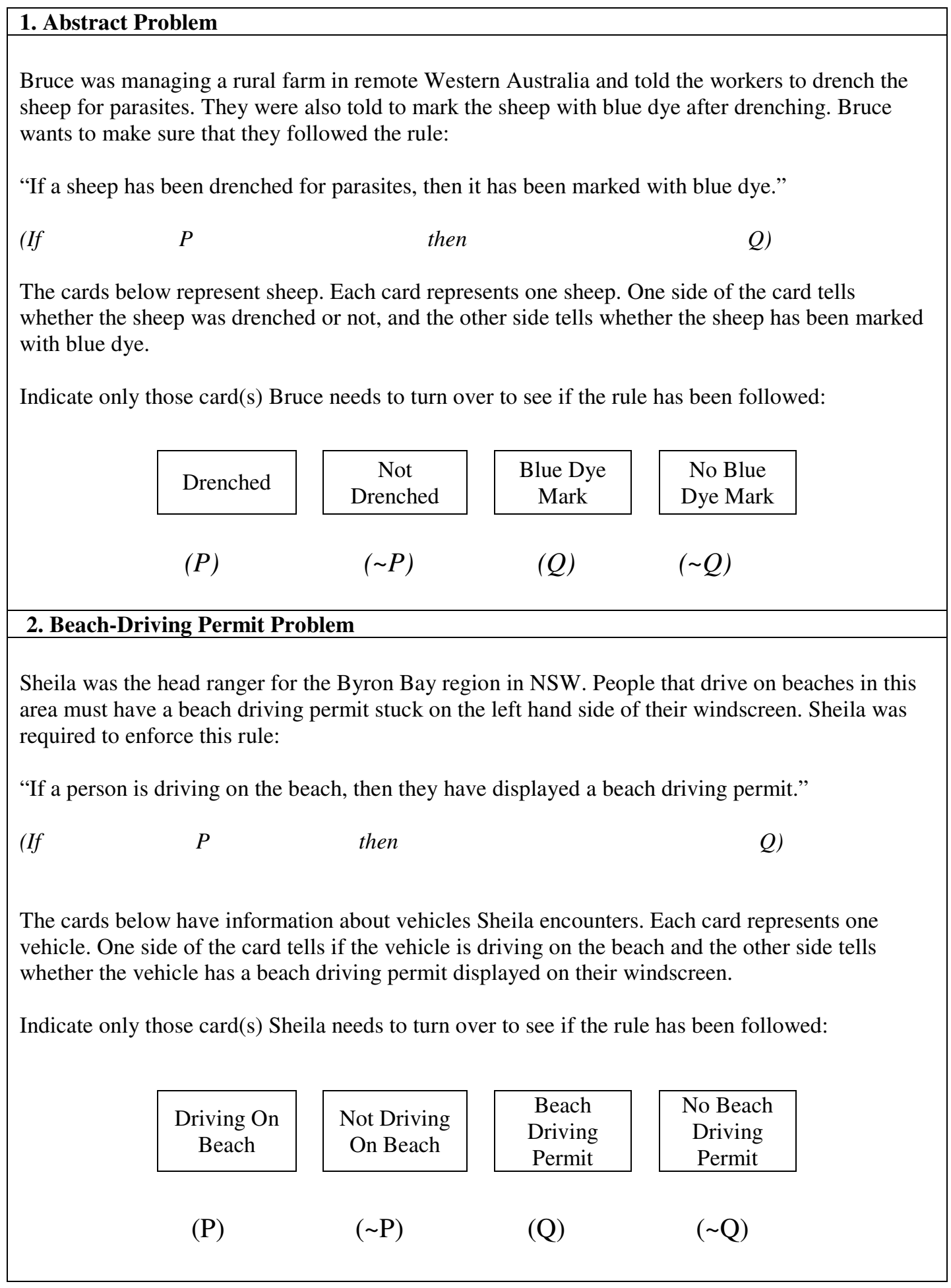

Figure 4. Two versions of the Wason card selection task, one an abstract problem and the other a problem concerning social exchange. 
Evolutionary Psychology is a large field (see Buss 2005 for a representative sample of current work), and it is associated not simply with the methodological approach just described, but also with a number of quite general conclusions about the human mind, conclusions to which many of those who describe themselves as Evolutionary Psychologists subscribe. Some of these conclusions are outlined in the next section.

\section{6. 'How the Mind Works'}

The classical ethologists based their ideas about mental mechanisms on the neuroscience of the inter-war years, when their program was being formulated. Evolutionary Psychology reflects the state of the sciences of the mind during its own formulation. In particular, the program was influenced by the dominant 'classical' school of cognitive science and the idea that the mind is computer software implemented in neural hardware (Marr 1982; Fodor 1983). Evolutionary Psychologists argue that the representational, information-processing language of classical cognitive science is ideal for describing the evolved features of the mind. Behavioral descriptions of what the mind does are useless because of the problem of changing environments described above. Neurophysiological descriptions are inappropriate, because behavioral ecology does not predict anything about the specific neural structures that underlie behavior. Models in behavioral ecology predict which behaviors would have been selected in the ancestral environment, but they cannot distinguish between different mechanisms that produce the same behavioral output. Hence, if one accepts the conventional view in cognitive science that many different neural mechanisms could potentially support the same behavior, it follows that behavioral ecology predicts little about the brain except which information-processing functions it must be able to perform:

When applied to behavior, natural selection theory is more closely allied with the cognitive level of explanation than with any other level of proximate causation. This is because the cognitive level seeks to specify a psychological mechanism's function, and natural selection theory is a theory of function. (Cosmides and Tooby 1987: 284)

It is thus slightly confusing that Evolutionary Psychologists talk of discovering psychological 'mechanisms', a term which suggests theories at the neurobiological level. What 'mechanism' actually refers to in this context is a performance profile - an account of what output the mind will produce given a certain range of inputs.

This fact that evolutionary reasoning yields expectations about the performance profile of the mind fits neatly with the explanatory framework of classical cognitive science. According to the influential account given in David Marr's book Vision (1982), explanation in cognitive science works at three, mutually illuminating levels. The highest level concerns the tasks that the cognitive system accomplishes - recovering the shape and position of objects from stimulation of the retina, for example. The lowest level concerns the neurophysiological mechanisms that accomplish that task - the neurobiology of the visual system. The intermediate level concerns the functional profile of those mechanisms, or as it is often described, the computational process that is implemented in the neurophysiology. Hypotheses about the neural realization of the 
computational level constrain hypotheses about computational processes: psychologists should only propose computational models that can be realized by neural systems. Conversely, hypotheses about computational processes guide the interpretation of neural structure: neuroscience should look for structures that can implement the required computations. Similar relations of mutual constraint hold between the level of task description and the level of computational processes. But there remains something of a puzzle as to how the highest level - the task description - is to be specified other than by stipulation. It seems obvious that the task of vision is to represent things around us, but what makes this true? According to Evolutionary Psychology, claims about task descriptions are really claims about evolution. The overall task of the mind is survival and reproduction in the ancestral environment and the sub-tasks performed by parts of the mind correspond to separate adaptive challenges posed by the ancestral environment. Obviously, it would have been useful for the ancestors of humans to be able to see, so it is predictable that humans will have a visual system. This kind of thinking becomes useful when the function of a psychological mechanism is not as blindingly obvious as in the case of vision. What, for example, is the task description for the emotion system, or for individual emotions such as jealousy or grief? Evolutionary Psychology argues that in such cases it should be evolutionary thinking that sets the agenda for cognitive science, telling it what to look for and how to interpret what it finds.

\subsection{The Massive Modularity Thesis}

One of the best-known claims of Evolutionary Psychology is the 'massive modularity thesis' or 'swiss army knife model', according to which the mind contains few if any general-purpose cognitive mechanisms. The mind is a collection of separate 'modules' each designed to solve a specific adaptive problem, such as mate-recognition or the enforcement of female sexual fidelity. The flagship example of a mental module is the 'Language Acquisition Device' - the mechanism that allows human infants to acquire a language in a way that it is widely believed would not be possible using any generalpurpose learning rules (Pinker 1994). The massive modularity thesis is an example of the kind of evolutionary guidance for cognitive science described in the last section. Evolutionary Psychology argues that evolution would favor multiple modules over domain general cognitive mechanisms because each module can be fine-tuned for a specific adaptive problem. So cognitive scientists should look for domain specific effects in cognition and should conceptualize their work as the search for and characterization of mental modules.

Evolutionary Psychologists often introduce the idea of modularity with examples from neuropsychology (e.g. Gaulin and McBurney 2001, 24-6). In these examples, 'double dissociation' studies, in which clinical or experimental cases show that each of two mental functions can be impaired whilst the other is performed normally, are used to support the claim that those two functions are performed by separate neural subsystems. But despite their use of these examples, Evolutionary Psychologists are quite clear that the mental modules in which they themselves are interested need not correspond to separate neural subsystems, nor be localized in specific regions of the brain (Gaulin and McBurney 2001, 26). The difference between 'neural subsystems' and 'mental modules' is 
instructive. The double dissociation experiment is a means for exploring structurefunction relationships in the brain. But for the purposes of evolution, what matters is not how the brain is structured, but how it appears to be structured when 'viewed' by natural selection. For Evolutionary Psychology, the fact that two functions are dissociated is significant in its own right, and not only as a clue to how those functions are instantiated in the brain. Thus, there are architectures that produce double dissociations but which neuropsychology regards as non-modular, cases where apparent double dissociations are simply misleading (Shallice 1988, 250). Evolutionary Psychology, in contrast, would regard these architectures as different ways to produce mental modularity. We might aptly term such mental modules 'virtual modules' (Griffiths In Press).

The modularity concept of Evolutionary Psychology derives from that developed in cognitive science of the early 1980s and popularized by Jerry Fodor in The Modularity of Mind (1983), but, once again, the differences are instructive. In Fodor's account, the definitive property of a module is 'informational encapsulation'. A system is informationally encapsulated if there is information unavailable to that system but which is available to the mind for other purposes. For example, in a phobic response the emotional evaluation of a stimulus ignores much of what the subject explicitly believes about the stimulus, suggesting that the emotional evaluation is informationally encapsulated. Fodor lists several other properties of modules, including domain specificity and the possession of proprietary algorithms. A system is domain specific if it only processes information about certain stimuli. It has proprietary algorithms if it treats the same information differently from other cognitive subsystems, something that Evolutionary Psychology identifies with the older idea that the module has 'innate knowledge'. The leading Evolutionary Psychologists Tooby and Cosmides make it clear that it is these two properties, rather than informational encapsulation, that are the two definitive properties of mental modules. A mental mechanism is simply not a module if "It lacks any a priori knowledge about the recurrent structure of particular situations or problem domains, either in declarative or procedural form, that might guide the system to a solution quickly." (1992, 104). In the Evolutionary Psychology literature the properties of being domain specific and of having proprietary algorithms are generally referred to simultaneously as 'functionally specialization'. Modules are "complex structures that are functionally organised for processing information" (1992, 33).

When Evolutionary Psychologists present experimental evidence of 'functionally specialization' in cognition, it is generally evidence suggesting that information about one class of stimuli is processed differently from information about another class of stimuli - that is, evidence of the use of different proprietary algorithms in the two domains. The interpretation of the Wason card selection task described above exemplifies this pattern of reasoning. In a similar vein, David Buss has argued that people leap to conclusions about sexual infidelity more readily than about other subjects. He uses this to support the view that there is a mental module for dealing with infidelity (Buss 2000). It seems that Evolutionary psychologists are simply not interested in cases where systems are domain specific but do not possess proprietary algorithms (this would be like having two identical PCs running identical software, one for personal use and the other for 
work). This is presumably because no evolutionary rationale can be imagined for such a neural architecture.

\subsection{The Monomorphic Mind Thesis}

Tooby and Cosmides have argued strongly for the 'monomorphic mind thesis' or 'psychic unity of humankind' $(1992,79)$. This states that differences in the cognitive adaptations of individual humans or human groups are not due to genetic differences. Instead, such differences are always, or almost always, due to environmental factors that trigger different aspects of the same developmental program. If true, this would make cognitive adaptations highly atypical, since most human traits display considerable individual variation related to differences in genotype. All human beings have eyes, but these eyes exhibit differences in color, size, shape, acuity and susceptibility to various forms of degeneration over time, all due to differences in genotype. It has been known for half a century that wild populations of most species contain substantial genetic variation, and humans are no exception.

Tooby and Cosmides offer one main argument for the conclusion that the genes involved in producing cognitive adaptations will be the same in all human individuals:

'Complex adaptations necessarily require many genes to regulate their development, and sexual recombination makes it combinatorially improbable that all the necessary genes for a complex adaptation would be together at once in the same individual, if genes coding for complex adaptations varied substantially between individuals. Selection, interacting with sexual recombination, enforces a powerful tendency towards unity in the genetic architecture underlying complex functional design at the population level and usually the species level as well.' (Tooby and Cosmides 1990, 393)

The authors apply this argument only to psychological adaptations, but its logic extends to all traits with many genes involved in their etiology. The argument seems to overlook the phenomena which the founders of modern neo-Darwinism referred to as 'genetic canalisation' or 'genetic homeostasis' and attributed to the effects of 'stabilising selection' (Schmalhausen 1949; Dobzhansky and Wallace 1953; Waddington 1957). Obviously, evolution will design developmental systems that are robust in the face of environmental variation, but in the middle of the last century new data from the genetics of natural populations indicated that it also designs them to be robust in the face of genetic variation. More or less identical 'wild type' phenotypes can be generated by a range of genotypes. This is why surprisingly many gene knock out experiments produce negative results. Development is robust and redundant. Disabling a gene known to be involved in a developmental pathway frequently produces no effect ('null phenotype'), because development contains positive and negative feedback mechanisms that increase transcription of the required gene product from the other allele, initiate transcription from another gene copy, or initiate transcription of a different gene product, and thereby achieve the same ends by different means (Freeman 2000; Wilkin 2003). 
Pacé Tooby and Cosmides, genetics and developmental biology provide no reason to accept the monomorphic mind thesis. Nor is there much direct evidence for the thesis. Behavioral geneticists have documented extensive heritable, individual differences in what are plausibly adaptive characters, such as IQ and personality, and some evolutionary psychologists have put this at the heart of their account of cognitive evolution (e.g. Miller 2000). One advantage of the thesis is that it makes it impossible to level accusations of racism against Evolutionary Psychology. But this defence is surely unnecessary. If it is assumed that variation in evolved human phenotypes roughly mirrors the known variation in human genotypes (Cavalli-Sforza, Menozzi, and Piazza 1994), then it follows that the vast majority of adaptive traits are pancultural and that any average differences between human groups will be dwarfed by the individual differences within those groups.

\section{Evolutionary psychology today}

Evolutionary Psychology is probably the largest school of evolutionary psychology at the present time, and it is certainly the most prominent in popular science (e.g. Pinker 1997). However, this particular school has some severe critics (see esp. Buller 2005; Fodor 2000) and many other approaches to evolutionary psychology continue to flourish. These are judiciously surveyed in Kevin Laland and Gillian Brown's Sense and Nonsense: Evolutionary perspectives on human behaviour (2002; see also Downes 2001). Two recent collections of papers also emphasize the diversity of ways in which evolution might be thought to inform psychological research (Heyes and Huber 2000; Scher and Rauscher 2002). Whilst scientists do not necessarily subscribe to a particular, selfconscious research program like Evolutionary Psychology, many can be classed as engaged in either 'human behavioral ecology', 'gene-culture co-evolution' or 'developmental evolutionary psychology'.

Human behavioral ecology is a research tradition derived from 'Darwinian anthropology', itself an offshoot of sociobiology (Cronk, Chagnon, and Irons 2000). Human behavioral ecologists continue to believe in the value of testing the predictions of behavioral ecology against contemporary human behavior. The Evolutionary Psychologists' critique of human sociobiology, summarized above, is that the rate of environmental change since the origins of human culture makes it irrational to expect human behavior to maximize reproductive fitness in modern environments. Some behavioral ecologists reply that adaptability is the hallmark of human evolution, so that it is no more irrational to expect humans to maximize their reproductive fitness in a modern city than to expect the rats who live in its sewers to do so (this view can be bolstered further by the 'nicheconstruction' perspective discussed below). Others emphasize the methodological virtues of a paradigm in which hypotheses can be tested directly, as opposed to one in which currently available evidence must be brought to bear on theories about an earlier phase in human evolutionary history. In the light of the discussion of Tinbergen above, we might add that whatever its bearing on evolutionary questions, research in human behavioral ecology could be justified simply by the intrinsic interest of the questions it addresses: how well do human beings survive and reproduce in modern environments and how they achieve this? 
Gene-culture coevolution is a flourishing scientific field that has its roots in two major theoretical works from the 1980s, Luca Cavalli-Sforza and Mark Feldman's Cultural Transmission and Evolution (1982) and Richard Boyd and Peter Richerson's Culture and the Evolutionary Process (1985). These authors developed mathematical models of change in culturally transmitted phenotypic characters in a population as a result of the differential ability of cultural variants to propagate themselves, and of the interaction between this process and genetic change in the same populations. In a flagship example, genetic differences in lactose tolerance in current human populations can be explained as a consequence of the spread of dairy farming, something that is clearly passed from one generation to the next - and from one human population to another - by cultural transmission. These two books have been widely praised for their mathematical sophistication, but criticized for providing 'consequence laws' while having no clear program for deriving the matching 'source laws' that would be needed to create a genuine evolutionary approach to culture (Sober 1992). There is, at present, no cultural equivalent of ecology to reveal how the interaction of cultural variants with their environment determines the differential fitness of those variants. During the 1990s gene-culture coevolution was to some extent subsumed under the more general concept of 'niche construction' (Odling-Smee, Laland, and Feldman 1996; Laland, Odling-Smee, and Feldman 2000; Odling-Smee, Laland, and Feldman 2003). Conventional evolutionary biology studies how populations change as a consequence of interactions with their environment. Niche-construction studies how environments change as a consequence of interactions with evolving populations. For example, the soil and climate of the Amazon basin are as much a consequence of the biota that has grown up there as of fundamental abiotic parameters such as longitude, topology, and underlying rock strata. On a smaller scale, beavers are exquisitely adapted to life in an environment - the beaver pond - that would not exist if it were not for the dam and lodge-building activities of beavers. Human being can be seen as the 'ultimate niche-constructors', in the sense that they modify their environment to a greater extent than any other single species. Rather than seeing humans as having evolved to live in small-scale hunter-gatherer societies and now having to improvise responses to the modern world using unsuitable mental mechanisms, geneculture co-evolution theory sees the relationship between the human mind and the modern world as more like that between the beaver and its dam. A recently published popular book and a collection of classic papers by Boyd and Richerson provide an excellent introduction to this alternative perspective (Boyd and Richerson 2005; Richerson and Boyd 2005).

Finally, a 'developmentalist' tradition in animal behavior research with its roots in classical ethology and comparative psychology has consistently criticized both sociobiology and Evolutionary Psychology for failing to integrate the evolutionary study of behavior with the study of how behavior develops (Gottlieb 1997; Bjorklund and Pellegrini 2002). Accessible introductions to this tradition have been provided by Patrick Bateson and Paul Martin (1999) and by David Moore (2001). Authors closer in orientation to Evolutionary Psychology have also stressed in recent years the importance of integrating evolutionary accounts of the mind with molecular developmental biology and with the neurosciences (e.g. Marcus 2004). If this trend continues evolutionary 
To appear in Blackwell's Companion to Philosophy of Biology, Sarkar, Sarkar and Plutynski, Anya (eds)

psychology may one day return to Tinbergen's project of constructing a single, integrated 'biology of behavior'.

\section{References}

Alexander, R. 1979. Darwinism and Human Affairs. Seattle: Washington University Press. 1987. The Biology of Moral Systems. New York: De Gruyter.

Baerends, G.P et al. 1976. Multiple Review of Wilson's Sociobiology'. Animal Behaviour 24:698-718.

Barash, D.P. 1979. Human ethology and human sociobiology. Behavioral and Brain Sciences 2 (1):26-27.

Barkow, J.H. 1979. Human ethology: Empirical wealth, theoretical dearth. Behavioral and Brain Sciences 2 (1):27.

Barkow, Jerome H, Leda Cosmides, and John Tooby, eds. 1992. The Adapted Mind: Evolutionary Psychology and the Generation of Culture. Oxford: Oxford University Press.

Bateson, Patrick P G, and Peter H Klopfer, eds. 1989. Whither Ethology? Vol. 8, Perspectives in Ethology. New York and London: Plenum.

Bateson, Patrick P G, and Paul Martin. 1999. Design for a Life: How behavior and personality develop. London: Jonathan Cape.

Bjorklund, David F, and Anthony D Pellegrini. 2002. The Origins of Human Nature: Evolutionary Developmental Psychology. Washington, DC: American Psychological Association.

Boyd, Robert, and Peter J Richerson. 1985. Culture and the Evolutionary Process. Chicago: Chicago University Press.

- 2005. The Origin and Evolution of Cultures. New York: Oxford University Press.

Buller, David J. 2005. Adapting Minds: Evolutionary Psychology and the Persistent Quest for Human Nature. Cambridge, MA: MIT Press/Bradford Books.

Burkhardt, Richard W. Jr. 2005. Patterns of Behavior: Konrad Lorenz, Niko Tinbergen and the Founding of Ethology. Chicago: University of Chicago Press.

Buss, D.M. 2000. The Dangerous Passion: Why Jealousy is as Essential as Love and Sex. New York: Simon and Schuster.

Buss, David M, ed. 2005. The Handbook of Evolutionary Psychology. Hoboken, NJ: Wiley.

Cavalli-Sforza, L.L, P Menozzi, and A Piazza. 1994. The History and Geography of Human Genes: Princeton University Press.

Cavalli-Sforza, Luca L, and Mark W Feldman. 1982. Cultural Transmission and Evolution: A Quantitative Approach. Princeton: Princeton University Press.

Cosmides, L, and J Tooby. 1987. From evolution to behaviour: Evolutionary psychology as the missing link. In The Latest on the Best: Essays on optimality and evolution, edited by J. Dupré. Cambridge, MA: MIT Press. 
To appear in Blackwell's Companion to Philosophy of Biology, Sarkar, Sarkar and Plutynski, Anya (eds)

1992. Cognitive adaptations for social exchange. In The Adapted Mind:

Evolutionary Psychology and the Generation of Culture, edited by J. H. Barkow, L. Cosmides and J. Tooby. Oxford, New York: Oxford University Press.

Crawford, C, M Smith, and D Krebs, eds. 1987. Sociobiology and Psychology: Ideas, Issues and Applications. New York: Lawrence Erlbaum Associates.

Cronk, L, N Chagnon, and W Irons, eds. 2000. Adaptation and Human Behavior: An Anthropological Perspective. New York: Aldine de Gruyter.

Darwin, C. 1965 [1872]. The Expression of the Emotions in Man and Animals. Chicago: University of Chicago.

1981 [1871]. The Descent of Man and Selection in Relation to Sex. Facsimile of the first edition ed. Princeton, NJ: Princeton University Press. Original edition, John Murray, London, 1871.

Dawkins, M.S, T.R Halliday, and R Dawkins, eds. 1991. The Tinbergen Legacy. London: Chapman and Hall.

Dawkins, Richard. 1976. The Selfish Gene. Oxford: Oxford University Press.

Dobzhansky, Theodosius, and Bruce Wallace. 1953. The Genetics of Homeostasis in Drosophila. Proc Nat Acad Sci USA 39 (3):162-171.

Downes, Stephen M. 2001. Some recent developments in evolutionary approaches to the study of human cognition and behavior. Biology and Philosophy 16 (5):575-595.

Dunlap, K. 1919. Are there any instincts? Journal of Abnormal Psychology 14:307-311.

Durant, John R. 1986. The making of ethology: The Association for the Study of Animal Behaviour, 1936-1986. Animal Behaviour 34:1601-1616.

Fodor, J. A. 1983. The Modularity of Mind: An Essay in Faculty Psychology. Cambridge, Mass: Bradford Books/MIT Press.

Fodor, J.A. 2000. The Mind Doesn't Work That Way: The Scope and Limits of Computational Psychology. Cambridge, Mass: MIT Press.

Freeman, M. 2000. Feedback control of intercellular signaling in development. Nature 408:313-319.

Gaulin, Stephen J.C, and Donald H. McBurney. 2001. Psychology: An Evolutionary Approach. Upper Saddle River, NJ: Prentice Hall.

Gottlieb, Gilbert. 1997. Synthesizing Nature-Nurture: Prenatal Roots of Instinctive Behavior. Hillsdale, NJ: Lawrence Erlbaum Assoc.

Griffiths, Paul E. In Press. Evo-Devo Meets the Mind: Towards a developmental evolutionary psychology. In Integrating Development and Evolution, edited by R. Sansom and R. N. Brandon. Cambridge: Cambridge University Press.

Hamilton, William D. 1964. The Genetical Evolution of Social Behaviour, I \& II. Journal of Theoretical Biology 7:1-16, 17-52.

Heyes, Celia M, and Ludwig Huber. 2000. The Evolution of Cognition, Vienna Series in Theoretical Biology. Cambridge, MA: MIT Press.

Hinde, R. A. 1956. Ethological Models and the Concept of 'Drive'. British Journal for the Philosophy of Science 6:321-331.

Kitcher, P. 1985. Vaulting Ambition: Sociobiology and the Quest for Human Nature. Cambridge, MA: M.I.T. Press.

Kuo, Z.Y. 1921. Giving up instincts in psychology. Journal of Philosophy 18:645-664. 
To appear in Blackwell's Companion to Philosophy of Biology, Sarkar, Sarkar and Plutynski, Anya (eds)

Laland, K. N, F. John Odling-Smee, and M.W Feldman. 2000. Niche construction, biological evolution and cultural change. Behavioral and Brain Sciences 23:131157.

Laland, Kevin N, and Gillian R Brown. 2002. Sense and nonsense: Evolutionary perspectives on human behaviour. Oxford ; New York: Oxford University Press.

Lehrman, Daniel S. 1953. Critique of Konrad Lorenz's theory of instinctive behavior. Quarterly Review of Biology 28 (4):337-363.

Lorenz, Konrad Z. 1950. The comparative method in studying innate behaviour patterns. Symposium of the Society of Experimental Biology 4 (Physiological Mechanisms in Animal Behaviour):221-268.

- 1996. The Natural Science of the Human Species: An Introduction to Comparative Behavioral Research. The Russian Manuscript (1944-1948). Translated by R. D. Martin. Cambridge, Mass: MIT Press.

Manning, Aubrey., and Marion Stamp Dawkins. 1998. An Introduction to Animal Behaviour. Cambridge: Cambridge University Press.

Marcus, Gary F. 2004. The birth of the mind: How a tiny number of genes creates the complexities of human thought. New York :: Basic Books,.

Marr, D. 1982. Vision. New York: W.H. Freeman.

Maynard Smith, J. 1982. Evolution and the theory of games. Cambridge: Cambridge University Press.

Maynard Smith, J, R Burian, S Kauffman, P Alberch, J Campbell, B Goodwin, R Lande, D Raup, and L Wolpert. 1985. Developmental Constraints and Evolution. Quarterly Review of Biology 60 (3):265-287.

Maynard Smith, John. 1987. How to model evolution. In The Latest on the Best: Essays on Optimality and Evolution, edited by J. Dupre. Cambridge, Mass.: MIT Press.

Miller, G. 2000. The Mating Mind. London: Heinemann.

Moore, David S. 2001. The Dependent Gene: The Fallacy of "Nature versus Nurture". New York: W.H Freeman/Times Books.

Odling-Smee, F. John, Kevin N Laland, and Marcus W Feldman. 1996. Niche Construction. American Naturalist 147 (4):641-648.

- 2003. Niche Construction: The Neglected Process in Evolution. Vol. 37, Monographs in Population Biology. Princeton, NJ: Princeton University Press.

Pinker, S. 1994. The Language Instinct: The New Science of Language and Mind. UK/US: Allen Lane/William Morrow.

- 1997. How the Mind Works. New York and London: Allen Lane.

Richards, R.J. 1987. Darwin and the Emergence of Evolutionary Theories of Mind and behavior. Chicago: Univ. of Chicago Press.

Richerson, Peter J, and Robert Boyd. 2005. Not by Genes Alone: How culture transformed human evolution. Chicago: University of Chicago Press.

Scher, S, and M Rauscher, eds. 2002. Evolutionary Psychology: Alternative Approaches. Dordrecht: Kluwer.

Schmalhausen, I.I. 1949. Factors of Evolution: The Theory of Stabilising Selection. Translated by I. Dordick. Philadelphia and Toronto: Blakeston.

Segerstråle, Ullica. 2000. Defenders of the Truth: The battle for science in the sociobiology debate and beyond. Oxford: Oxford University Press. 
Shallice, T. 1988. From Neuropsychology to Mental Structure. Cambridge: Cambridge University Press.

Slater, Peter J. B. 2003. Fifty years of bird song research: A case study in animal behaviour. Animal Behaviour 65:633-639.

Sober, Elliott. 1984. The Nature of Selection: Evolutionary Theory in Philosophical Focus. Cambridge, MA: MIT Press.

- 1992. Models of Cultural Evolution. In Trees of Life: Essays in the Philosophy of Biology, edited by P. E. Griffiths. Dordrecht: Kluwer Academic Publishers.

Tinbergen, N. 1951. The Study of Instinct. Oxford: Oxford University Press.

_ 1963. The Work of the Animal Behaviour Research Group in the Department of Zoology, University of Oxford. Animal Behaviour 11:206-209.

Tinbergen, Niko. 1985. Watching and Wondering. In Leaders in the Study of Animal Behavior: Autobiographical Perspectives, edited by D. A. Dewsbury. London and Toronto: Associated University Presses.

Tinbergen, Nikolaas. 1963. On the aims and methods of ethology. Zietschrift für Tierpsychologie 20:410-433.

Tooby, J, and L Cosmides. 1990. The past explains the present: emotional adaptations and the structure of ancestral environments. Ethology and Sociobiology 11:375424.

1992. The Psychological Foundations of Culture. In The Adapted Mind: Evolutionary Psychology and the Generation of Culture, edited by J. H. Barkow, L. Cosmides and J. Tooby. Oxford and New York: Oxford University Press.

Trivers, R. L. 1971. The evolution of reciprocal altruism. Quarterly Review of Biology 46 (4):35-57.

Waddington, Conrad H. 1957. The Strategy of the Genes: A Discussion of Some Aspects of Theoretical Biology. London: Ruskin House/George Allen and Unwin Ltd.

Wilkin, Adam. 2003. Canalization and Genetic Assimilation. In Keywords and Concepts in Evolutionary Developmental Biology, edited by B. K. Hall and W. M. Olson. Cambridge, MA and London: Harvard University Press.

Wilson, E.O. 1975. Sociobiology: The New Synthesis: Harvard University Press. 